\title{
Recruitment of enzymes and stress proteins as lens crystallins
}

\author{
Joram Piatigorsky, Marc Kantorow, Rashmi Gopal-Srivastava and Stanislav I. Tomarev
}

Laboratory of Molecular and Developmental Biology, National Eye Institute, National Institutes of Health, Bethesda, Maryland 20892

\section{Summary}

The major water-soluble proteins - or crystallins - of the eye lens are either identical to or derived from proteins with non-refractive functions in numerous tissues. In general, the recruitment of crystallins has come from metabolic enzymes (usually with detoxification functions) or stress proteins. Some crystallins have been recruited without duplication of the original gene (i.e., lactate dehydrogenase B and $\alpha$-enolase), while others have incurred one (i.e., argininosuccinate lyase and a small heat shock protein) or several (i.e., glutathione S-transferase) gene duplications. Enzyme (or stress protein)-crystallins often maintain their non-refractive function in the lens and/or other tissues as well as their refractive role, a process we call gene sharing. $\alpha$-Crystallin/small heat shock protein $/ \mathrm{molecular}$ chaperone is of special interest since it is the major crystallin of humans. There are two $\alpha$-crystallin genes ( $\alpha \mathrm{A}$ and $\alpha \mathrm{B})$, with $\alpha \mathrm{B}$ retaining the full functions of a small heat shock protein. Here we describe recent evidence indicating that $\alpha \mathrm{A}$ and $\alpha \mathrm{B}$ have kinase activity, which would make them members of the enzyme-crystallins. We also describe various regulatory elements of the mouse $\alpha$-crystallin genes responsible for their expression in the lens and, for $\alpha \mathrm{B}$, in skeletal muscle. Delineating the control elements for gene expression of these multifunctional protective proteins provides the foundations for their eventual use in gene therapy. Finally, comparison of the mouse and chicken $\alpha \mathrm{A}-$ crystallin genes reveals similarities and differences in their functional cis-acting elements, indicative of evolution at the level of gene regulation.

\section{Introduction}

Since the role of the transparent eye lens is to focus light onto the retina it has been assumed that its characteristic crystallins, which account for approximately $90 \%$ of the soluble proteins of the lens, are highly specialized for this refractive function. However, the crystallins are a surprisingly diverse, developmentally regulated group of proteins which often vary quantitatively and qualitatively among species in a taxon-specific manner (see Wistow and Piatigorsky, 1988). Moreover, many of the crystallins are present in low concentrations in numerous non-lens tissues, consistent with their having non-refractive functions. Sequence data have shown, unexpectedly, that a large number of the crystallins are related to or identical with metabolic enzymes, and may retain enzymatic activity in the lens (see Piatigorsky and Wistow, 1989; de Jong et al., 1989; Piatigorsky, 1992; Wistow, 1993). In addition, the $\alpha$-crystallins, which are present in all vertebrate lenses, are derived from the small heat shock proteins (sHSPs), with $\alpha \mathrm{B}$-crystallin continuing to serve as a sHSP and both $\alpha \mathrm{A}$ and $\alpha \mathrm{B}$ being able to act as a molecular chaperone (Horwitz, 1992; see de Jong et al., 1993). 
The dual use of a metabolic enzyme or stress protein for refraction in the lens without loss of its original function in other tissues has been called gene sharing (see Piatigorsky and Wistow, 1989). The pragmatic use of the same protein for entirely different roles in different tissues implies that the innovation of new functions for a protein is associated with changes in the regulation of its gene (see Piatigorsky and Wistow, 1991; Piatigorsky, 1992). We have thus been studying the molecular basis for the recruitment of enzymes and stress proteins as crystallins at the level of gene regulation. Greater understanding of the mechanisms generating high expression of these genes in different tissues is clearly relevant to their eventual utilization for different medical purposes through induction and gene therapy.

\section{Results and Discussion}

\section{The taxon-specific enzyme-crystallins}

Many different enzymes have been recruited as lens crystallins (Fig. 1). Although these so-called enzyme-crystallins are not related by any single activity or metabolic pathway, many have detoxification functions. The recruitment of detoxification enzymes as crystallins is not limited to vertebrates, but has also occurred among the invertebrates which have convergently evolved

TAXON-SPECIFIC CRYSTALLINS

\begin{tabular}{|c|c|c|c|}
\hline Distribution & Crystallin & (Related) or Identical & Activity \\
\hline Most birds and reptiles & $\begin{array}{l}\delta 1 \\
\delta 2\end{array}$ & $\begin{array}{l}\text { (argininosuccinate lyase) } \\
\text { argininosuccinate lyase }\end{array}$ & $\bar{t}$ \\
\hline Duck, crocodile & $\varepsilon$ & lactate dehydrogenase B & + \\
\hline $\begin{array}{l}\text { Guinea pig, camel, } \\
\text { degus, rock cavy, llama }\end{array}$ & $\zeta$ & $\begin{array}{l}\text { (alcohol dehydrogenase) } \\
\text { quinone oxido reductase (novel) }\end{array}$ & $\overline{+}$ \\
\hline Elephant shrews & $\eta$ & $\frac{\text { cytoplasmic aldehyde }}{\text { dehydrogenase }}$ & - \\
\hline Rabbits, hares & $\lambda$ & $\begin{array}{l}\text { (hydroxyl CoA dehydrogenase) } \\
\text { (vat-1 [membrane protein, syn. vesicle }\end{array}$ & (el) \\
\hline Australian marsupials & $\mu$ & (ornithine cyclodeaminase) & - \\
\hline Frog & $\rho$ & $\begin{array}{l}\text { (NADPH-aldo-keto reductases) } \\
\mathrm{PGH}_{2} 9,11 \text {-endoperoxide reductase } \\
\end{array}$ & $\overline{+}-$ \\
\hline Many vertebrates & $\tau$ & $\alpha$-enolase & + \\
\hline \multirow[t]{2}{*}{ Cephalopods } & $\mathrm{S}$ & $\begin{array}{l}\text { (glutathione S-transferases) } \\
\text { glutathione S-transferase }\end{array}$ & $+\overline{+}$ \\
\hline & $\Omega /$ & (aldehyde dehydrogenase) & - \\
\hline $\begin{array}{l}\text { Gastropods } \\
\text { (Aplysia) }\end{array}$ & $\mathrm{NN}^{+}$ & novel proteins $(80,63 \mathrm{kDa})$ & $?$ \\
\hline Jellyfish & J1 & novel proteins $(35,20,19 \mathrm{kDa})$ & $?$ \\
\hline
\end{tabular}

$+\mathrm{NN}$, not named.

Fig. 1. The phylogenetic distribution and activity of the taxon-specific crystallins. 
complex eyes with cellular lenses. The best studied example is the cephalopod (squid and octopus) eye whose major crystallins (S-crystallins) are related to glutathione S-transferase (Tomarev et al., 1992). Cephalopods (especially octopus) also have a minor crystallin ( $\Omega$-crystallin) derived from aldehyde dehydrogenase (Zinovieva et al., 1993). It is interesting to note that cytoplasmic class I aldehyde dehydrogenase has also been recruited as a crystallin ( $\eta$-crystallin) in the elephant shrew (Wistow and Kim, 1991) and class III aldehyde dehydrogenase may serve a refractive function in the transparent corneal epithelial cells of mammals, where it comprises as much as $40 \%$ of the soluble protein (Cuthbertson et al., 1992). The derivations and functions, if any, of the Aplysia and jellyfish crystallins are not known (see Piatigorsky, 1992).

\section{Recruitment of crystallins from enzymes and stress proteins}

Three different mechanisms have been used to recruit lens crystallins at the gene level (see Piatigorsky, 1992 and Wistow, 1993 for reviews) (Fig. 2). The first dispenses with gene duplication, using the identical gene encoding the metabolic enzyme as a crystallin. $\epsilon$ Crystallin/lactate dehydrogenase B (LDHB) and $\tau$-crystallin/ $\alpha$-enolase are two examples of recruitment without gene duplication. In these cases, the recruitment of the enzyme as a crystallin depends upon changes in gene regulation leading to high expression in the lens. Any changes in enzyme activity depend on posttranscriptional modifications in the lens, since the structural gene must continue to encode an active enzyme for use in different tissues. The second mechanism involves one duplication of the original enzyme or stress protein, with $\delta$ crystallin/argininosuccinate lyase (ASL) and $\alpha$-crystallin/small heat shock protein (sHSP) representing these cases (Fig. 2). In both of these examples, one of the duplicated genes has specialized as a crystallin, although it is still expressed in some non-lens cells; the other duplicated gene is also expressed most highly in the lens but has retained all of its original nonrefractive functions in numerous tissues. Finally, the third mechanism used to recruit lens crystallins involves multiple duplications of the original enzyme. For example, there are at least $10 \mathrm{~S}$-crystallin genes in the squid that were derived from the glutathione S-transferase (GST) gene (Tomarev et al., 1993). The S-crystallin genes are expressed only in the lens and cornea and, except for very slight GST activity of one of the S-crystallins (SL11) (Tomarev, Chung and Piatigorsky, unpublished), they lack enzymatic function (Tomarev et al., 1992). The S-crystallin genes encoding the inactive enzyme derivatives have acquired an additional exon which probably contributes to the loss of enzyme activity of the crystallin. 
RECRUITMENT OF CRYSTALLIN GENES

\begin{tabular}{|c|c|c|c|c|c|}
\hline Original Gene & & Crystallin Genes & $\begin{array}{l}\text { Enzyme or } \\
\text { Non-refractive } \\
\text { Activity }\end{array}$ & $\begin{array}{l}\text { Lens } \\
\text { Expression }\end{array}$ & Examples \\
\hline Lactate dehydrogenase B & $\stackrel{\text { No Duplication }}{\longrightarrow}$ & $\varepsilon / \mathrm{LDH}_{\mathrm{B}}$ & + & Preferred & Duck \\
\hline$\alpha$-Enolase & No Duplication & $\tau / \alpha$-enolase & + & Preferred & Duck \\
\hline Argininosuccinate lyase & $\stackrel{\text { One Duplication }}{\longrightarrow}$ & $\delta 1+\delta 2 / A S L$ & $\left.\begin{array}{l}\delta 1- \\
\delta 2+\end{array}\right\}$ & Preferred & Chicken, Duck \\
\hline Small heat shock protein & $\underset{\text { One Duplication }}{\longrightarrow}$ & $\alpha A+\alpha B / s H S P$ & $\left.\begin{array}{l}\alpha A+? \\
\alpha B+\end{array}\right\}$ & Preferred & Mouse, Rat \\
\hline Glutathione S-transferase & $\underset{\text { Duplications }}{\stackrel{\text { Several }}{\longrightarrow}}$ & $\begin{array}{l}\text { SL11+SL20-1+SL20-3 } \\
\text { +Other Genes }\end{array}$ & $\left.\begin{array}{l}\text { SL11+1- } \\
\text { Others }-\end{array}\right\}$ & Specific & Squid \\
\hline
\end{tabular}

Fig. 2. Crystallin recruitment from enzymes or stress proteins has occurred without gene duplication $(\epsilon-$ crystallin/LDHB and $\tau$-crystallin/ $\alpha$-enolase), with one gene duplication ( $\delta$-crystallin/ASL and $\alpha$-crystallin/sHSP) and with several gene duplications (S-crystallin/GST).

\section{The $\alpha$-crystallins}

The two $\alpha$-crystallins ( $\alpha \mathrm{A}$ and $\alpha \mathrm{B}$ ) are particularly interesting because they are present in all vertebrates and are the major crystallins of the human lens. $\alpha \mathrm{A}$ is expressed highly only in the lens, however it has also been reported to be present a low concentrations in other tissues, especially the spleen and thymus (Kato et al., 1991; Srinivasan et al., 1992). $\alpha \mathrm{B}$ continues to be an active member of the sHSP family and is expressed constitutively in many different tissues as well as being inducible by physiological stress (Dubin et al., 1989; Bhat and Nagineni, 1989; Dasgupta et al., 1992; Klemenz et al., 1991b). In general, the accumulation of $\alpha \mathrm{B}$-crystallin outside of the lens has been correlated with cells of high oxidative activity (see Sax and Piatigorsky, 1993 and de Jong et al., 1993 for reviews). The structure and expression pattern of the two $\alpha$-crystallin genes are shown in Fig. 3.

Stimuli resulting in the induction of $\alpha \mathrm{B}$-crystallin include oncogene (Ha-ras, v-mos) expression, osmotic stress, heat shock, dexamethasone, cadmium, sodium arsenite, and stretching of skeletal muscle. $\alpha \mathrm{B}$-crystallin is also overexpressed in numerous diseases, especially neuro (and other) degenerative diseases, such as scrapie-infection in hamster brains, and Alexander's disease, Creutzfeldt-Jacob disease, Lewy body disease, amyotrophic lateral sclerosis, Werner's syndrome, and Parkinson's disease in humans (see Sax and Piatigorsky, 1993, and Piatigorsky, 1993 for more complete discussion and references). An especially rele- 

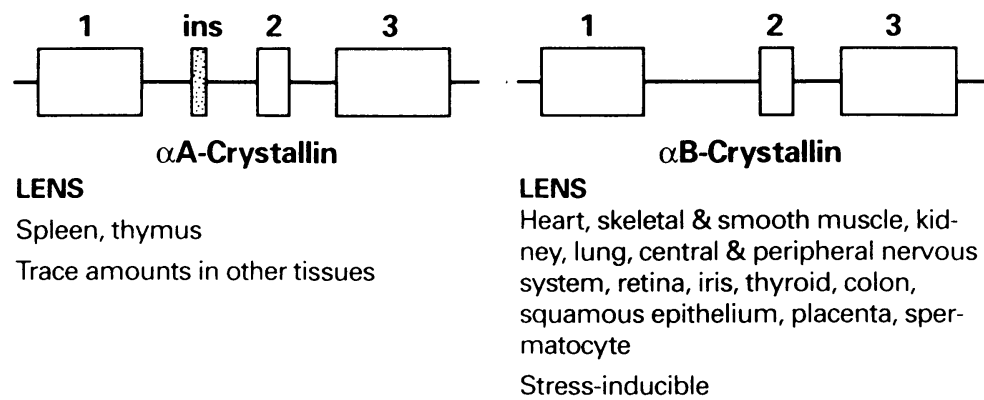

Fig. 3. Diagrammatic structures of the $\alpha \mathrm{A}$ - and $\alpha \mathrm{B}$-crystallin genes. The boxes represent exons and the lines introns. Both are expressed principally in the lens and to a lesser extent in the other tissues listed. The stippled box in the $\alpha \mathrm{A}$-crystallin gene is the insert exon whose RNA is alternatively spliced into the mRNA in rodents and some other mammals to create the $\alpha \mathrm{A}^{\text {ins }}$-crystallin polypeptide (see Wistow and Piatigorsky, 1988).

vant case for the present symposium is the accumulation of $\alpha \mathrm{B}$-crystallin in ubiquitinated inclusion bodies (Mallory bodies) of alcoholic liver disease (Lowe et al., 1992). It seems likely that protection against protein denaturation is at least one of the functions of $\alpha \mathrm{B} / \mathrm{sHSP}$ in these stressed cells in view its chaperone activity (Horwitz, 1992).

Is $\alpha$-crystallin a kinase?

A proportion of both $\alpha$-crystallin polypeptides are phosphorylated in the lens, and previous experiments in cell-free extracts have implicated a cyclic AMP-dependent kinase in this process (Spector et al., 1985; Voorter et al., 1986). Recently we have found that purified native $\alpha$ crystallin or its individual polypeptides from bovine lenses (a kind gift of Dr. Joseph Horwitz, UCLA School of Medicine) become phosphorylated in a magnesium-dependent, cyclic AMPindependent manner in the presence of ${ }^{32} \mathrm{P}-\gamma$-ATP (Kantorow and Piatigorsky, in preparation) (Fig. 4). While we cannot yet be certain that a separate kinase does not contaminate the $\alpha$ crystallin preparations, the data suggest that $\alpha$-crystallin posseses kinase activity, in particular for autophosphorylation. If $\alpha$-crystallin is a kinase it joins the family of enzyme-crystallins and makes enzyme-crystallins present in all vertebrates, including humans. Moreover, this would be the first indication that small heat shock proteins have kinase activity and would fit with sequence data suggesting distant similarities between functional domains of small and large heat 
shock proteins of eukaryotes and prokaryotes (Lee et al., 1993). Finally, kinase activity by $\alpha$ crystallin raises the possibility that this refractive protein/sHSP/molecular chaperone participates in one or more signal transduction pathways, providing new avenues of research for its high expression in growing tissues such as NIH 3T3 cells expressing oncogenes (Klemenz et al., 1991a), astrocytic tumors of neuroectodermal origin (Iwaki et al., 1991) and benign harmatomas (Iwaki and Tateishi, 1991). It is of interest in this connection that other sHSPs have been linked to cell growth and differentiation (see de Jong et al., 1993). Thus, if $\alpha$-crystallin is indeed a kinase, it would be a trifunctional protein with the capacity to serve a number of structural and metabolic roles.

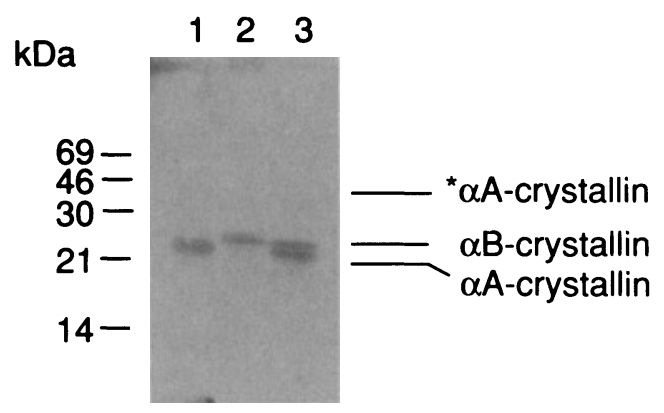

Fig. 4. Autoradiogram of a sodium dodecyl sulfate-polyacrylamide gel of purified $\alpha \mathrm{A}$-crystallin (lane 1), $\alpha \mathrm{B}$ crystallin (lane 2), or mixture of $\alpha \mathrm{A}$ and $\alpha \mathrm{B}$ polypeptides (lane 3) after incubation with ${ }^{32} \mathrm{P}-\gamma$-ATP for 60 minutes at $37^{\circ} \mathrm{C}$. The band labeled ${ }^{*} \alpha \mathrm{A}$ is a dimer.

\section{Molecular basis for $\alpha B$-crystallin gene expression}

Initial transfection and transgenic mouse experiments using a mouse $\alpha \mathrm{B}$-crystallin minigene lacking introns (Dubin et al., 1989) and 5' flanking sequences from the $\alpha \mathrm{B}$ gene fused to the bacterial chloramphenicol acetyltransferase (CAT) reporter gene (Dubin et al., 1991) established that expression of the $\alpha \mathrm{B}$ gene in skeletal muscle, heart and lens is regulated by transcription. Additional transfection experiments using the human growth hormone gene driven by the Herpes simplex thymidine kinase promoter fused to 5' flanking sequences of the mouse $\alpha \mathrm{B}$-crystallin gene revealed the existence of an enhancer at positons -426 to -257 of the $\alpha \mathrm{B}$ gene which leads to high expression in the mouse $\mathrm{C} 2 \mathrm{C} 12$ muscle cell line (especially after myotube formation in culture) and weaker expression in the mouse $\alpha \mathrm{TN} 4-1$ lens cell line (which is transformed with the simian virus 40 large $\mathrm{T}$-antigen) and the rabbit N/N1003A lens cell line (which is not transformed) (Dubin et al., 1991). Recently we have identified by DNase I footprinting, site-specific 
mutagenesis and transfection assays three regulatory sites ( $\alpha \mathrm{BE}-1, \alpha \mathrm{BE}-2$ and $\alpha \mathrm{BE}-3)$ within the $\alpha \mathrm{B}$ enhancer which function in both the muscle and lens cells and one regulatory site (MRF) which functions specifically in the muscle cells (Gopal-Srivastava and Piatigorsky, 1993). The $\alpha \mathrm{BE}-2$ site contains an AP-2-like sequence (TTCCCCTGG) and the MRF site contains an E box consensus sequence (CAGCTG); the region between the $\alpha \mathrm{BE}-1$ and $\alpha \mathrm{BE}-2$ sites contains a heat shock sequence (CCTAGGAAGATTCC). The results of immunological tests and co-transfection experiments in NIH 3T3 cells are consistent with one or more members of the $\mathrm{MyoD} / \mathrm{myogenin}$ family of transcription factors being functional components of the MRF transcription complex. Finally, transgenic mice carrying 5' flanking sequences of the $\alpha \mathrm{B}$-crystallin gene $(-426 /+44)$ fused to the CAT gene confirmed that the sequence containing the $\alpha \mathrm{B}$ enhancer leads to CAT expression specifically in skeletal muscle, heart and lens; by contrast, DNase I footprinting and transgenic mice carrying a shorter 5' flanking sequence of the $\alpha \mathrm{B}$ gene $(-164 /+44)$ fused to the CAT gene identified a lens-specific regulatory sequence (-147/-118) (Gopal-Srivastava and Piatigorsky, in preparation). Thus, the selective expression of the $\alpha \mathrm{B}$-crystallin gene in different tissues is controlled in part by the utilization of different regulatory sequences.

\section{Molecular basis for $\alpha A$-crystallin gene expression}

Although not absolutely lens-specific, the $\alpha \mathrm{A}$-crystallin gene is more specialized for lens expression than is the $\alpha \mathrm{B}$ gene and, in contrast to the $\alpha \mathrm{B}$ gene, does not appear to be inducible by physiological stress. Comparison of the 5' flanking regions of the $\alpha \mathrm{A}$-crystallin genes of mice, chicken and humans shows three highly conserved sequences (Jaworski et al., 1991). These have been called DE1 (-111/-94), $\alpha$ A-CRYBP1 (-67/-40) and TATA/PE-1 $(-35 /+12)$ in the mouse. Relatively little sequence similarity exists further upstream than position -111 of these three species. Transfection experiments involving site-specific mutations, electrophoretic mobility shift assays and cloning of a putative transcription factor called $\alpha \mathrm{A}-\mathrm{CRYBP} 1$ (Nakamura et al., 1990; Kantorow et al., 1993) and transgenic mice (Sax et al., 1993) have pointed to the functional importance of the $\alpha \mathrm{A}-\mathrm{CRYBP} 1$ site in the mouse gene.

Surprisingly, however, experiments using the $\alpha \mathrm{A}$-crystallin gene of the chicken have indicated that different regulatory mechanisms underlie the function of this orthologous gene. Initial transfection experiments showed that the poorly conserved sequence between position -162 and 121 is essential for activity of the chicken promoter in transfected lens cells (Klement $e t$ al., 1989). Moreover, transfection experiments using a series of site-specific linker-scanning 
mutations indicated that the $\alpha \mathrm{A}-\mathrm{CRYBP} 1$ site is not necessary for activity of the chicken promoter (Klement et al., 1993). This result fits with a previous demonstration that an oligonucleotide containing the core sequence of the chicken $\alpha$ A-CRYBP1 site (GAGAAATCCC) attached to the viral thymidine kinase promoter was unable to drive the CAT gene in transfected lens cells, while the core of the $\alpha \mathrm{A}-\mathrm{CRYBP} 1$ site of the mouse, which differs from the chicken sequence in its second nucleotide (GGGAAATCCC), was functional in the transfected cells (Sax et al., 1990). Further analysis has shown that numerous cis-acting elements not present in the mouse gene are critical for promoter activity of chicken $\alpha \mathrm{A}$-crystallin gene (Matsuo and Yasuda, 1992; Klement et al., 1993; see Sax and Piatigorsky, 1993). Nonetheless, a transgene containing 242 base pairs of 5' flanking sequence of the chicken $\alpha$ A-crystallin gene fused to the CAT gene functions with lens-specificity in transgenic mice (Klement et al., 1989), indicating that some common features must exist for regulation of the chicken and the mouse $\alpha \mathrm{A}$-crystallin genes.

\section{Conclusions}

A wealth of sequence and functional data has shown that numerous metabolic enzymes (often with detoxification roles) and a SHSP have been recruited to become crystallins and contribute to the refractive properties of the transparent cellular lens of vertebrates and invertebrates. In some cases crystallin recruitment has involved one or several gene duplications, while in other cases it has occurred without gene duplication. Often at least one crystallin gene has retained some or all of its original non-refractive function and may continue to be used in non-lens tissues for its non-refractive role, a process we call gene sharing. Thus, changes in the regulation of gene activity lies at the heart of the recruitment process. Differences in the control elements of the mouse and chicken $\alpha \mathrm{A}$-crystallin gene provide a glimpse of the dynamism of the evolutionary process at the level of gene regulation. Gene sharing leaves open the possibility that virtually any gene may have two or more unrelated roles (see Piatigorsky and Wistow, 1991), raising concerns for gene therapy. The $\alpha \mathrm{B}$-crystallin gene is of special interest for eventual gene therapy against physiological stress in view of its multiple control elements, its powerful ability to protect proteins from denaturation, and its possible role in cellular growth and differentiation.

\section{References}

Bhat, S.P. and Nagineni, C.N. (1989) $\alpha$ B subunit of lens-specific $\alpha$-crystallin in other ocular and non-ocular tissues. Biochem. Biophys. Res. Comm. 158: 319-325. 
Cuthbertson, R.A., Tomarev, S.I. and Piatigorsky, J. (1992) Taxon-specific recruitment of enzymes as major soluble proteins in the corneal epithelium of three mammals, chicken, and squid. Proc. Natl. Acad. Sci. USA 89: 4004-4008.

Dasgupta, S., Hohman, T.C. and Carper, D. (1992) Hypertonic stress induces $\alpha$ B-crystallin expression. Exp. Eye Res. 54: 461-470.

de Jong, W.W., Hendriks, W., Mulders, J.W.M. and Bloemendal, H. (1989) Evolution of eye lens crystallins: the stress connection. TIBS 14: 365-368.

de Jong, W.W., Leunissen, J.A.M., and Voorter, C.E.M. (1993) Evolution of the $\alpha$ crystallin/small heat shock protein family. Mol. Cell. Biol. 10: 103-126.

Dubin, R.A., Gopal-Srivastava, R., Wawrousek, E.F. and Piatigorsky, J. (1991) Expression of the murine $\alpha \mathrm{B}$-crystallin gene in lens and skeletal muscle: identification of a muscle-preferred enhancer. Mol. Cell. Biol. 11: 4340-4349.

Dubin, R.A., Wawrousek, E.F. and Piatigorsky, J. (1989) Expression of the murine $\alpha$ Bcrystallin gene is not restricted to the lens. Mol. Cell. Biol. 9: 1083-1091.

Gopal-Srivastava, R. and Piatigorsky, J. (1993) The murine $\alpha$ B-crystallin/small heat shock protein enhancer: identification of $\alpha \mathrm{BE}-1, \alpha \mathrm{BE}-2, \alpha \mathrm{BE}-3$, and MRF control elements. Mol. Cell. Biol. 13: 7144-7152.

Horwitz, J. (1992) $\alpha$-crystallin can function as a molecular chaperone. Proc. Natl. Acad. Sci. USA 89: 10449-10453.

Iwaki, T., Iwaki, A., Miyazono, M. and Goldman, J.E. (1991) Preferential expression of $\alpha$ Bcrystallin in astrocytic elements of neuroectodermal tumors. Cancer 68: 2230-2240.

Iwaki, T. and Tateishi, J. (1991) Immunohistochemical demonstration of alphaB-crystallin in harmatomas of tuberous sclerosis. Am. J. Path. 139: 1303-1308.

Jaworski, C.J., Chepelinsky, A.B. and Piatigorsky, J. (1991) The $\alpha$ A-crystallin gene: conserved features of the 5' flanking regions in human, mouse, and chicken. J. Mol. Biol. 33: 495-505.

Kantorow, M., Becker, K., Sax, C.M., Ozato, K. and Piatigorsky, J. (1993) Binding of tissuespecific forms of $\alpha \mathrm{A}-\mathrm{CRYBP} 1$ to its regulatory sequence in the mouse $\alpha \mathrm{A}$-crystallin gene: double-label immunoblotting of UV-crosslinked complexes. Gene 131: 159-165.

Kato, K., Shinohara, H., Kurobe, N., Goto, S., Inaguma, Y. and Ohshima, K. (1991) Immunoreactive $\alpha \mathrm{A}$-crystallin in rat non-lenticular tissues detected with a sensitive immunoassay method. Biochim. Biophys. Acta 1080: 173-180.

Klement, J.F., Wawrousek, E.F. and Piatigorsky, J. (1989) Tissue-specific expression of the chicken $\alpha \mathrm{A}$-crystallin gene in cultured lens epithelia and transgenic mice. J. Biol. Chem. 264: 19837-19844.

Klement, J.F., Cvekl, A. and Piatigorsky, J. (1993) Functional elements DE2A, DE2B, and DE1A and the TATA box are required for activity of the chicken $\alpha$ A-crystallin gene in transfected lens epithelial cells. J. Biol. Chem. 268: 6777-6784.

Klemenz, R., Frohli, E., Aoyama, A., Hoffmann, S., Simpson, R.J., Moritz, R.L., and Schafer, R. (1991a) $\alpha$ B-crystallin accumulation is a specific response to Ha-ras and v-mos oncogene expression in mouse NIH 3T3 fibroblasts. Mol. Cell. Biol. 11: 803-812.

Klemenz, R., Frohli, E., Steiger, R.H., Schafer, R. and Aoyama, A. (1991b) $\alpha$ B-crystallin is a small heat shock protein. Proc. Natl. Acad. Sci. USA 88: 3652-3656.

Lee, D.C., Kim, R.Y. and Wistow, G.J. (1993) An avian $\alpha$ B-crystallin: non-lens expression and sequence similarities with both small (HSP27) and large (HSP70) heat shock proteins. J. Mol. Biol. 232: 1221-1226.

Matsuo, I. and Yasuda, K. (1992) The cooperative interaction between two motifs of an 
enhancer element of the chicken $\alpha \mathrm{A}$-crystallin gene, $\alpha \mathrm{CE} 1$ and $\alpha \mathrm{CE} 2$, confers lens-specific expression. Nucl. Acids Res. 20: 3701-3712.

Nakamura, T., Donovan, D.M., Hamada, K., Sax, C.M., Norman, B., Flanagan, J.R., Ozato, K., Westphal, H. and Piatigorsky, J. (1990) Regulation of the mouse $\alpha$ A-crystallin gene: isolation of a cDNA encoding a protein that binds to a cis sequence motif shared with the major histocompatibility complex class I gene and other genes. Mol. Cell. Biol. 10: 37003708.

Piatigorsky, J. (1992) Lens crystallins. Innovation associated with changes in gene regulation. J. Biol. Chem. 267: 4277-4280.

Piatigorsky, J. and Wistow, G.J. (1989) Enzyme/crystallins: gene sharing as an evolutionary strategy. Cell 57: 197-199.

Piatigorsky, J. and Wistow, G.J. (1991) The recruitment of crystallins: new functions precede gene duplication. Science 252: 1078-1079.

Sax, C.M., Ilagan, J.G. and Piatigorsky, J. (1993) Functional reduncancy of the DE-1 and $\alpha$ ACRYBP1 regulatory sites of the mouse $\alpha \mathrm{A}$-crystallin promoter. Nucl. Acids Res. 21: 26332640.

Sax, C.M., Klement, J.F. and Piatigorsky, J. (1990) Species-specific lens activation of the thymidine kinase promoter by a single copy of the mouse $\alpha$ A-CRYBP1 site and loss of tissue specificity by multimerization. Mol. Cell. Biol. 10: 6813-6816.

Sax, C.M. and Piatigorsky, J. (1993) Expression of the $\alpha$-crystallin/small heat shock protein/molecular chaperone genes in the lens and other tissues. Adv. Enzymol., in press.

Srinivasan, A.N., Nagineni, C.N. and Bhat, S.P. (1992) $\alpha$ A-crystallin is expressed in nonocular tissues. J. Biol. Chem. 267: 23337-23341.

Spector, A., Chiesa, R., Sredy, J. and Garner, W. (1985) cAMP-dependent phosphorylation of bovine lens $\alpha$-crystallin. Proc. Natl. Acad. Sci. USA 82: 4712-4716.

Tomarev, S.I., Zinovieva, R.D., Guo, K. and Piatigorsky, J. (1993) Squid glutathione Stransferase. Relationships with other glutathione S-transferases and S-crystallins of cephalopods. J. Biol. Chem. 268: 4534-4542.

Tomarev, S.I., Zinovieva, R.D. and Piatigorsky, J. (1991) Crystallins of the octopus lens. Recruitment from detoxification enzymes. J. Biol. Chem. 266: 24226-24231.

Tomarev, S.I., Zinovieva, R.D. and Piatigorsky, J. (1992) Characterization of squid crystallin genes. Comparison with mammalian glutathione S-transferase genes. J. Biol. Chem. 267: 8604-8612.

Voorter, C.E.M., Mulders, J.W.M., Bloemendal, H. and de Jong, W.W. (1986) Some aspects of the phosphorylation of $\alpha$-crystallin A. Eur. J. Biochem. 160: 203-210.

Wistow, G. (1993) Lens crystallins: gene recruitment and evolutionary dynamism. TIBS 18: 301-306.

Wistow, G.J. and Kim, H. (1991) Lens protein expression in mammals: taxon-specificity and the recruitment of crystallins. J. Mol. Evol. 32: 262-269.

Wistow, G.J. and Piatigorsky, J. (1987) Recruitment of enzymes as lens structural proteins. Science 236: 1554-1556.

Wistow, G.J. and Piatigorsky, J. (1988) Lens crystallins: The evolution and expression of proteins for a highly specialized tissue. Annu. Rev. Biochem. 57: 479-504.

Zinovieva, R.D., Tomarev, S.I. and Piatigorsky, J. (1993) Aldehyde dehydrogenase-derived $\Omega$ crystallins of squid and octopus. Specialization for lens expression. J. Biol. Chem. 268: 11449-11455. 